\title{
Sulfur Atomically Doped Bismuth Nanobelt Driven from Electrochemical Self-Reconstruction for Boosted Electrocatalysis
}

Yunxiang Lin, ${ }^{1 \S}$ Li Yang, ${ }^{1,3 \S}$ Hongliang Jiang, ${ }^{1,4}$ Youkui Zhang, ${ }^{1,2}$ Yanan Bo ${ }^{1}$, Ping Liu $^{l}$, Shuangming Chen ${ }^{l}$, Bin Xiang ${ }^{1}$, Guang Li ${ }^{3}$, Jun Jiang ${ }^{1}$, Yujie Xiong ${ }^{l}$ and Li Song ${ }^{1 *}$

${ }^{1}$ National Synchrotron Radiation Laboratory, School of Chemistry and Materials Science, University of Science and Technology of China, Hefei, Anhui 230029, China ${ }^{2}$ School of National Defense Science and Technology, Southwest University of Science and Technology, Mianyang, Sichuan 621010, China

${ }^{3}$ Institute of Physical Science and Information Technology, School of Physics and Materials Science, Anhui University, Hefei, Anhui 230601, China

${ }^{4}$ School of Chemical Engineering, East China University of Science and Technology, Shanghai 200237, China

AUTHOR INFORMATION

Corresponding Author

*song2012@ustc.edu.cn (L.S.) 


\section{EXPERIMENTAL SECTION}

\section{Preparation of $\mathrm{Bi}_{2} \mathrm{~S}_{3}$ nanobelt:}

The $\mathrm{Bi}_{2} \mathrm{~S}_{3}$ nanobelt was synthesis by reacting $\mathrm{Bi}\left(\mathrm{NO}_{3}\right)_{3} \cdot 5 \mathrm{H}_{2} \mathrm{O}$ and $\left(\mathrm{NH}_{4}\right)_{2} \mathrm{~S}$ through hydrothermal methods: First, $1 \mathrm{mmol}(485 \mathrm{mg})$ of $\mathrm{Bi}\left(\mathrm{NO}_{3}\right)_{3} \cdot 5 \mathrm{H}_{2} \mathrm{O}$ was dissolved in $20 \mathrm{~mL}$ deionized water (DI water) under magnetic stirring for $30 \mathrm{~min}$; Then, $10 \mathrm{~mL}$ of $\left(\mathrm{NH}_{4}\right)_{2} \mathrm{~S}$ solution was added into the $\mathrm{Bi}\left(\mathrm{NO}_{3}\right)_{3} \cdot 5 \mathrm{H}_{2} \mathrm{O}$ solution and keep stirring for another $30 \mathrm{~min}$; Final, the obtained mixed liquid was transferred into Teflon vessel maintained at $160{ }^{\circ} \mathrm{C}$ in an autoclave for $3 \mathrm{~h}$. The final products were collected and dried under vacuum after washed by DI water and ethanol for several times.

\section{Preparation of Bi nanobelt as contrast sample:}

Typically, the Bi nanobelt was synthesized as the previous report: Firstly, $40 \mathrm{~mL}$ of $5 \mathrm{M} \mathrm{NaH} 2 \mathrm{PO}_{2} \cdot \mathrm{H}_{2} \mathrm{O}, 100 \mathrm{mg}$ of $\mathrm{H}_{2} \mathrm{C}_{4} \mathrm{H}_{4} \mathrm{O}_{6}, 500 \mathrm{mg}$ of $\mathrm{NaOH}$ and $75 \mathrm{~mL}$ of DI water were mixed in a three-necked flask. After vigorously string for $20 \mathrm{~min}$, then 5 $\mathrm{mL}$ of $1 \mathrm{M} \mathrm{Bi}\left(\mathrm{NO}_{3}\right)_{2}$ solution with $0.0096 \mathrm{~mol} \mathrm{HNO}_{3}$ was added to the obtained solution and the $\mathrm{pH}$ value was adjusted to 2.5. After the solution was changed from white to dark gray, the three-neck flask was transferred to water bath with $60{ }^{\circ} \mathrm{C}$ and keep string for $6 \mathrm{~h}$. The result precipitates were filtered and washed with DI water and ethanol for several times. The Bi nanobelt was obtained after dried under vacuum overnight.

\section{Characterizations:}

Powder X-ray diffraction (XRD) was carried out on a Philips X'Pert Pro Super diffractometer equipped with $\mathrm{Cu} \mathrm{K} \alpha$ radiation $(\lambda=1.54178 \AA$ ). Synchrotron radiation X-ray photoelectron spectroscopy (SR-XPS) was detected at the Catalysis and Surface Science End Station at the BL11U beamline of National Synchrotron Radiation Laboratory (NSRL) under different incident light energy. The binding energy were calibrated by using the $\mathrm{Au} 4 \mathrm{f}$ as a reference. Transmission electron microscopy (TEM) and high-resolution TEM (HRTEM) measurement were taken on a JEM-2100F field emission electron microscopy at an acceleration voltage of $200 \mathrm{kV}$. 
The Bi L ${ }_{3}$-edge XAFS spectra were collected at the Shanghai Synchrotron Radiation Facility (BL14W1, SSRF) and Beijing Synchrotron Radiation Facility (1W1B, BSRF). The energy difference between the two facilities was corrected by comparing the absorption edge of $\mathrm{Bi}$ foil. The XAFS data were collected by transmission mode under fixed photon energy range. The obtained XAFS data were further analyzed by the ATHENA and ARTMIS software containing FEFF package. Firstly, we fitted the FT-EXAFS spectrum of standard Bi foil to further get the fitting parameters of S-Bi. Then, the coordination number of S-Bi was fitted by using the CIF data of Bi.

\section{Preparation of S-doped Bi and procedure for NRR tests:}

In this work, carbon paper (CP, Tory 060) was used as the current collector. To prevent the potential pollution from $\mathrm{CP}$, the $\mathrm{CP}$ was firstly soaked in $\mathrm{H}_{2} \mathrm{SO}_{4}$ solution for $12 \mathrm{~h}$ and washed with ethanol and water for several times and dried under vacuum overnight. The Nafion 117 membrane was pre-treated according to the standard procedures provided by DuPont Company. In order to dislodge the residual $\mathrm{NH}_{4}^{+}$ from the source materials, the obtained $\mathrm{Bi}_{2} \mathrm{~S}_{3}$ was dipped in $0.5 \mathrm{M} \mathrm{H}_{2} \mathrm{SO}_{4}$ string under magnetism for $12 \mathrm{~h}$, then washed by DI water and ethanol for several times. The S-Bi working electrode was fabricated via an in-situ electrochemical reduction reaction using $\mathrm{Bi}_{2} \mathrm{~S}_{3}$ nanobelt as precursor. Detailly, $5 \mathrm{mg}$ of $\mathrm{Bi}_{2} \mathrm{~S}_{3}$ nanobelt was dispersed into $1 \mathrm{~mL}$ ethanol solution containing $50 \mu \mathrm{L} 5 \mathrm{wt} \%$ Nafion ionomer and ultrasonic dispersion for $2 \mathrm{~h}$ to obtain the uniform ink. Then, $120 \mu \mathrm{L}$ of the uniform ink was dropped on CP with exposed area of $1 * 1 \mathrm{~cm}^{2}$ (calculated Bi loading: $0.5 \mathrm{mg} \mathrm{cm}^{-2}$ ) and dried under vacuum environment overnight (named as Bi $2 \mathrm{~S}_{3} @ \mathrm{CP}$ ). To obtain S-Bi nanobelt, the prepared Bi $\mathrm{S}_{3} @ \mathrm{CP}$ was activated under -0.9 V (vs RHE) for $1 \mathrm{~h}$ in a standard three-electrode system. Finally, the S-Bi@CP can be obtained by rinsing (using DI water and ethanol). The working electrode was preserved under vacuum to avoid to be oxidized before NRR test.

Electrochemical data were collected with a CHI660E electrochemical workstation. Standard H-cell with three electrode system was used in the 
electrochemical NRR measurement in which an $\mathrm{Ag} / \mathrm{AgCl}$ electrode was used as a reference electrode, and a Pt mesh was used as a counter electrode. The $0.1 \mathrm{M} \mathrm{NaSO}_{4}$ solution was used as the electrolyte and purged by $\mathrm{N}_{2}$ overnight to exclude potential pollution. In addition, the feeding gas $\left(\mathrm{N}_{2}, 99.999 \%\right)$ was purged into the chamber with a continuously rate of $20 \mathrm{sccm}$ during the whole electrocatalytic process. To avoid the potential random error during the test, the working electrode was soaked in $10 \mathrm{~mL}$ of electrolyte for $2 \mathrm{~h}$ to exclude the contamination before NRR test. To further collect the exceeded ammonia, an acid trap with $5 \mathrm{~mL}$ of $0.5 \mathrm{M} \mathrm{H}_{2} \mathrm{SO}_{4}$ was connected to the chamber. Before chronoamperometry test, the work electrode was scans for several times to obtain a stable current signal, then the electrolytes was replaced by fresh $\mathrm{Na}_{2} \mathrm{SO}_{4}$ solution. In addition, all the chronoamperometry tests were repeated 3 times to avoid radom error. The stability test was performed by replacing the electrolyte every $2 \mathrm{~h}$ without changing the work electrode and membrane.

\section{Determine of ammonia:}

Here, the concentration of yield ammonia in the electrolyte was detected by indophenol blue indicator through UV-vis absorption spectra. The determine of ammonia can be concluded as follows:

(a) Preparing stock reagent: Reagent A (Chromogenic reagent): $5 \mathrm{~g}$ of sodium salicylate and $5 \mathrm{~g}$ potassium sodium tartrate were dissolved into $100 \mathrm{~mL}$ of $1 \mathrm{M}$ $\mathrm{KOH}$. Reagent B (Oxidizing solution): $3.5 \mathrm{~mL}$ of sodium hypochlorite was added into $100 \mathrm{~mL}$ of DI water. Reagent C (Catalyzing solution): $200 \mathrm{mg}$ of sodium nitroferricyanide was dissolved into $20 \mathrm{~mL}$ of DI water.

UV-vis measurement: $2 \mathrm{~mL}$ of sample solution was added to the test tube with $2 \mathrm{~mL}$ of reagent $\mathrm{A}, 1 \mathrm{~mL}$ of reagent $\mathrm{B}$ and $0.2 \mathrm{~mL}$ of reagent $\mathrm{C}$. After shaking up and standing for $1 \mathrm{~h}$, the concentration of as-prepared sample solution was detected by using UV-vis spectrophotometer.

\section{Determine of hydrazine:}

We further carried out the Watt and Chrisp method to detect the possible hydrazine product. $2.0 \mathrm{~g}$ of para-(dimethylamino) benzaldehyde was dissolved in a 
mixture of $10 \mathrm{~mL}$ concentrated $\mathrm{HCl}$ and $100 \mathrm{~mL}$ ethanol. The as-prepared sample solution was mixed into the chromogenic reagent by using UV-vis spectrophotometer at $460 \mathrm{~nm}$.

\section{Calculation of Faradaic efficiency:}

The FE was calculated as follows: $\mathrm{FE}=3 \mathrm{~F} \times \mathrm{c} \times \mathrm{V} /(17 \times \mathrm{Q})$

F: Faraday constant; c: measured $\mathrm{NH}_{3}$ concentration; V: volume of the electrolyte; Q: the total charge used for the electrodes.

\section{Details of DFT calcinations:}

Spin-polarized density functional theory (DFT) calculations were performed via the Vienna ab initio Simulation Package (VASP) ${ }^{1}$ The electronic exchange-correlation effects were described by the Perdew-Burke-Ernzerhof (PBE) parameterization $^{2}$ within generalized gradient approximation (GGA). ${ }^{3}$ The projector-augmented wave (PAW) pseudopotential ${ }^{4}$ was selected to simulate the interactions between core and valence electrons in atoms and ions. Van der Waals correction was considered for the dispersion correction. The surface model of perfect $\mathrm{Bi}$ and $\mathrm{S}$-doped $\mathrm{Bi}$ were constructed with a five-layer slab in which the bottom two layers were fixed. A $15 \AA$ vacuum along the $\mathrm{z}$ direction was added to the surfaces. The energy cutoff was set to be $450 \mathrm{eV}$ for the plane-wave expansion. The energy convergence criteria of geometry relaxation were chosen to be $10^{-4} \mathrm{eV}$, and the convergence criteria for max force was $0.02 \mathrm{eV} / \AA$. A $2 \times 3 \times 1 \mathrm{k}$-point grid was sampled for the calculated systems.

The Gibbs free energy change of each NRR step was calculated according to the equation: ${ }^{5} \Delta \mathrm{G}=\Delta \mathrm{E}+\Delta \mathrm{E}_{\mathrm{ZPE}}-\mathrm{T} \Delta \mathrm{S}$, wherein $\Delta \mathrm{E}$ stands for the DFT calculated reaction energy. $\Delta \mathrm{E}_{\mathrm{ZPE}}$ denotes the zero-point energy correction and $\Delta \mathrm{S}$ is the entropy change, both of which were computed by the vibrational frequencies of the adsorbed species, the temperature was set to be $298.15 \mathrm{~K}$. Meanwhile, it should be noted that the chemical potential of $\left(\mathrm{H}^{+}+\mathrm{e}^{-}\right)$pair was set to be half of the chemical potential of hydrogen $\left(\mathrm{H}_{2}\right){ }^{6}$ 


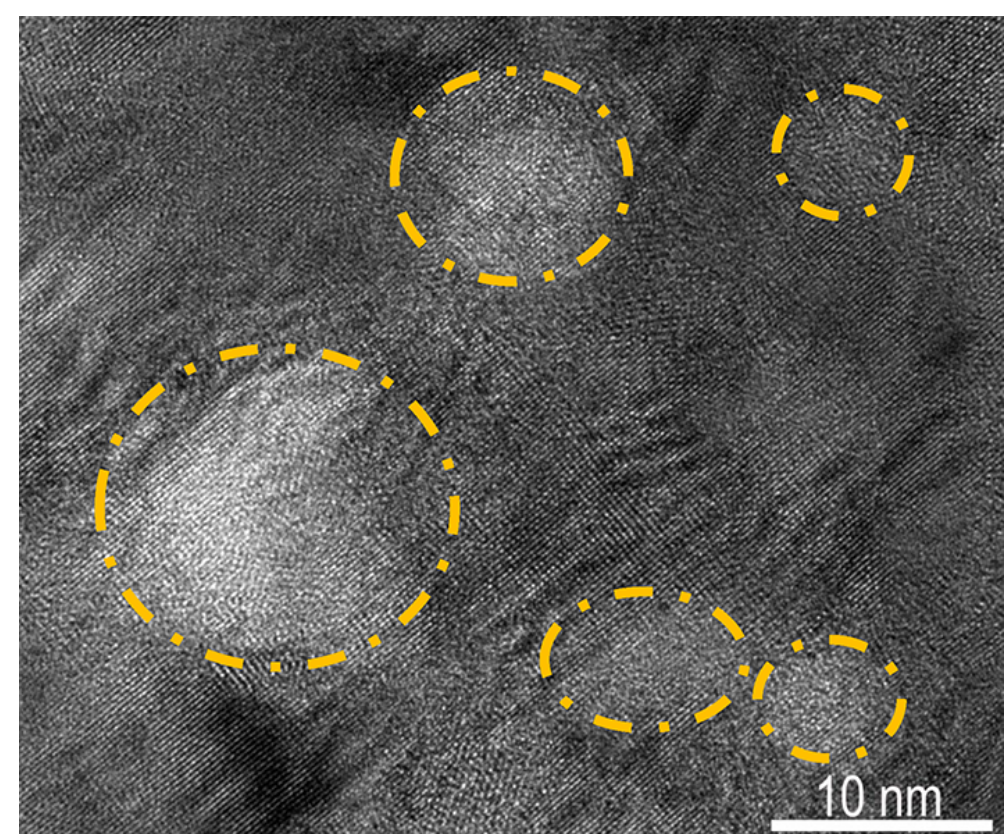

Figure S1. Enlarged TEM image of S-Bi. 


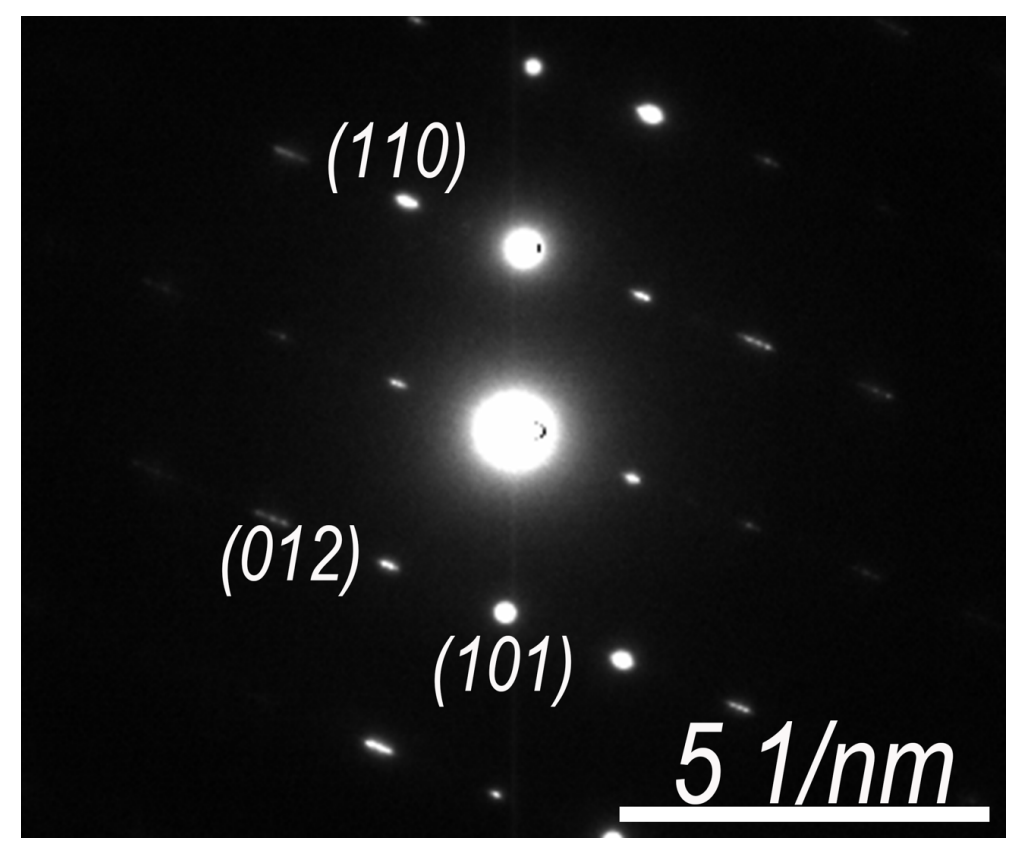

Figure S2. SAED pattern of S-Bi. 


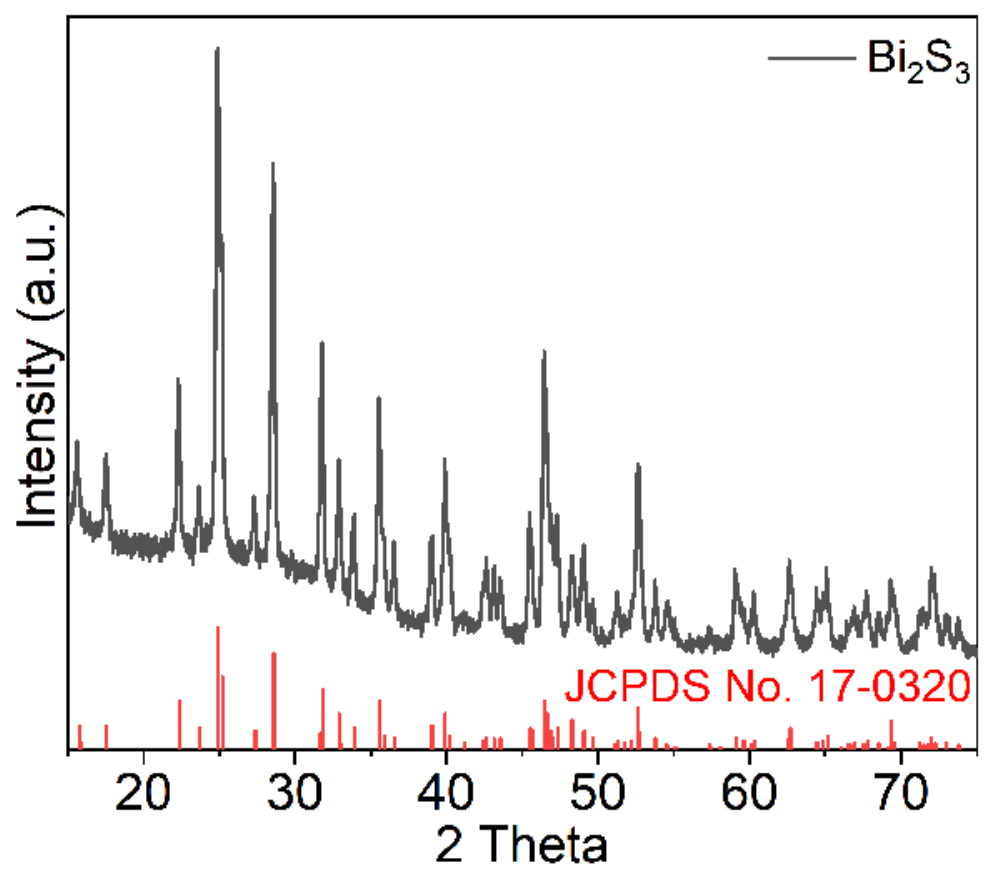

Figure $\mathrm{S} 3$. XRD pattern of $\mathrm{Bi}_{2} \mathrm{~S}_{3}$ and corresponded standard JCPDS data. 


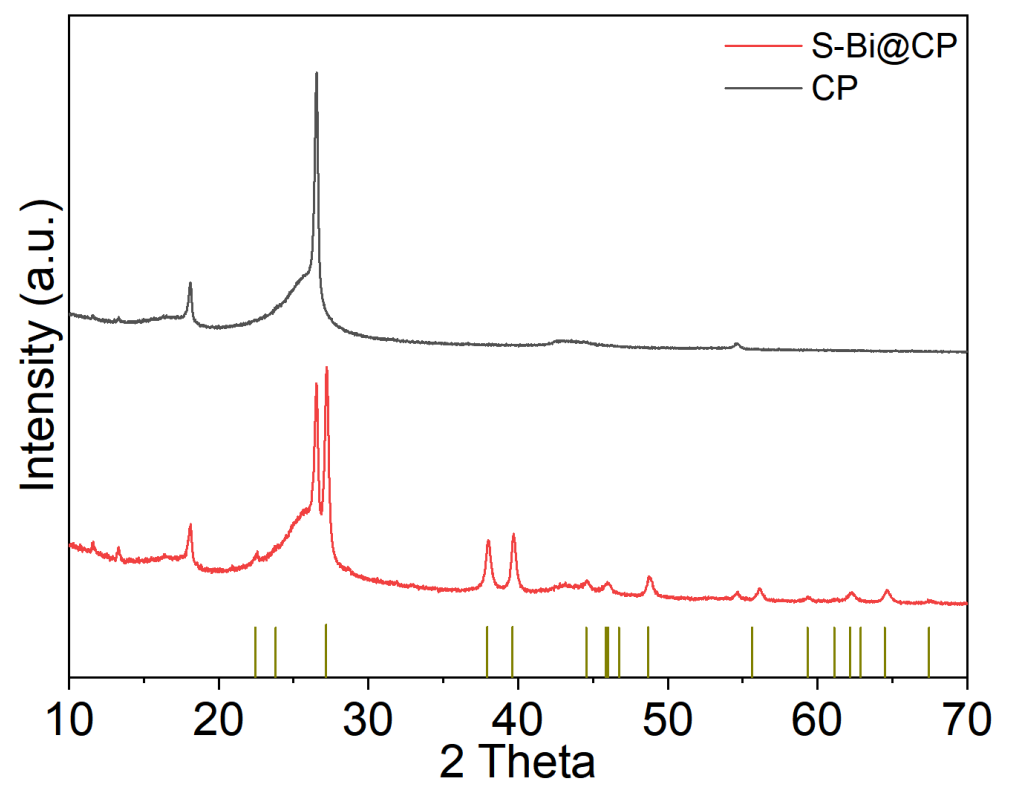

Figure S4. XRD pattern of carbon paper and S-Bi@CP. A series diffraction peak locates at $11.5^{\circ}, 13.3^{\circ}, 18.0^{\circ}, 26.5^{\circ}$ and $54.5^{\circ}$ can be observed. 

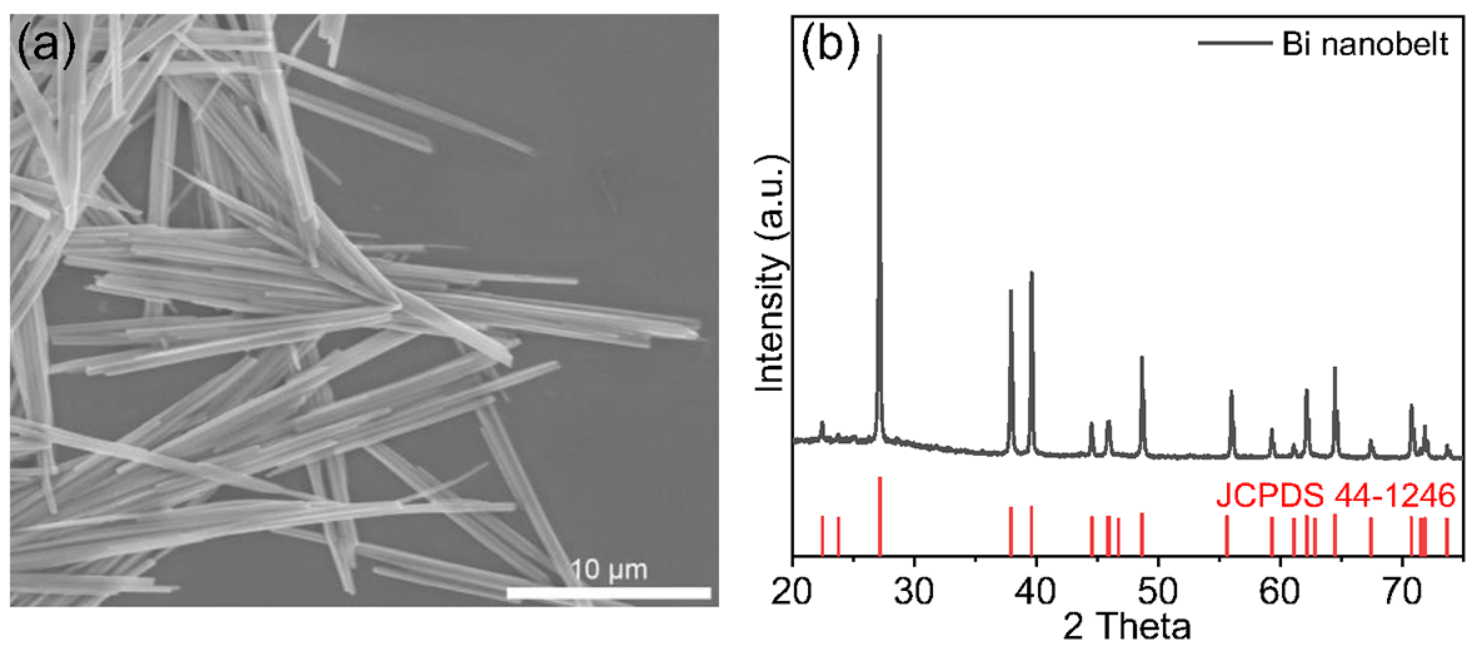

Figure S5. (a) SEM image and XRD pattern of pure Bi nanobelt as the contrast sample. 


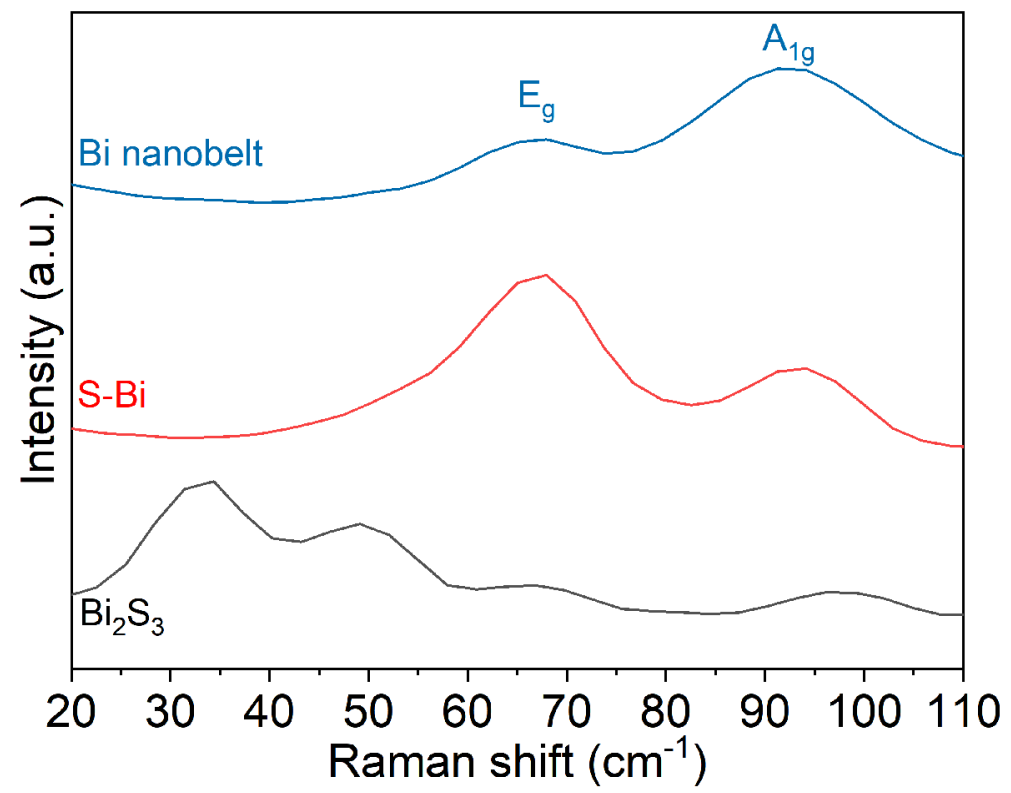

Figure S6. Raman spectra of $\mathrm{S}-\mathrm{Bi}$, Bi nanobelt and $\mathrm{Bi}_{2} \mathrm{~S}_{3}$. 

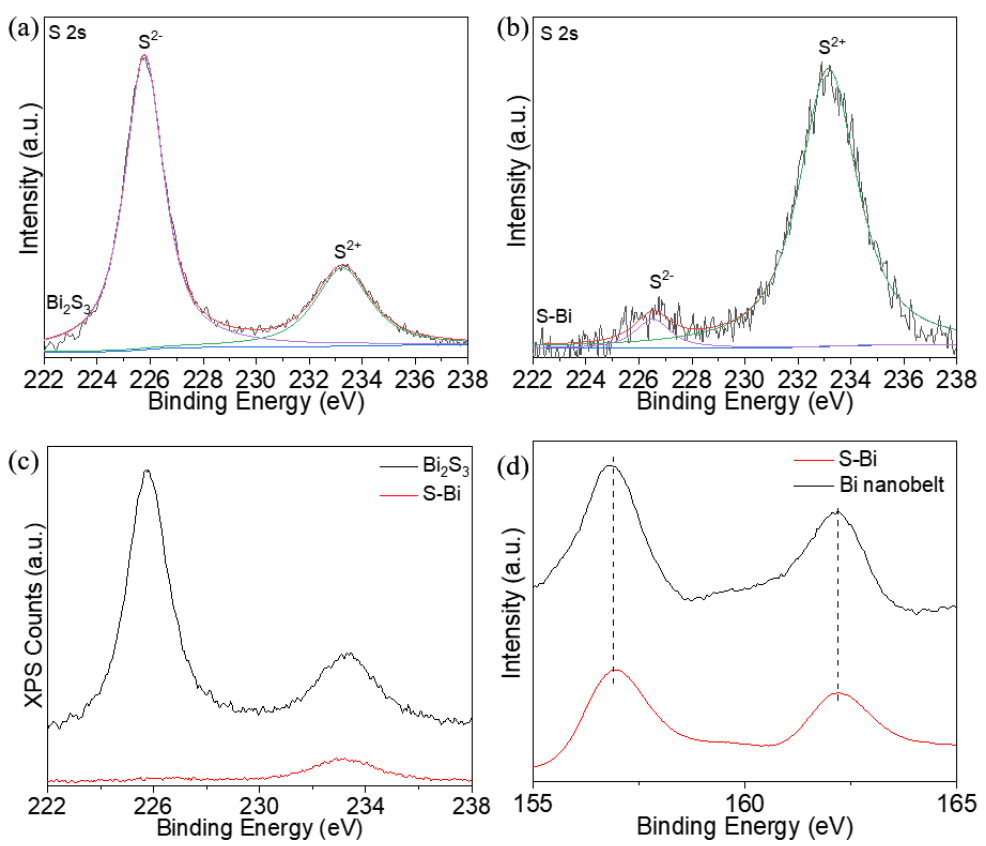

Figure S7. S 2s XPS spectra of (a) $\mathrm{Bi}_{2} \mathrm{~S}_{3}$ and (b) S-Bi and (c)the comparison of XPS counts of these two samples. (d) Bi $4 \mathrm{f}$ XPS spectra of $\mathrm{S}-\mathrm{Bi}$ and as-prepared $\mathrm{Bi}$ nanobelt.

The S 2s spectra exhibit two main peaks locate at $225.8 \mathrm{eV}$ and $233.2 \mathrm{eV}$, corresponding to the Bi-S and S-O, respectively. As can be seen from the Figure S8, the Bi-S bond is sharply decreased after reduction while the $\mathrm{S}-\mathrm{O}$ bond keep the same. As illustrated in Figure s4d, there are no distinguished difference of the Bi $4 \mathrm{f}$ XPS spectra between the S-Bi and Bi nanobelt, indicating the similar chemical states of Bi. 


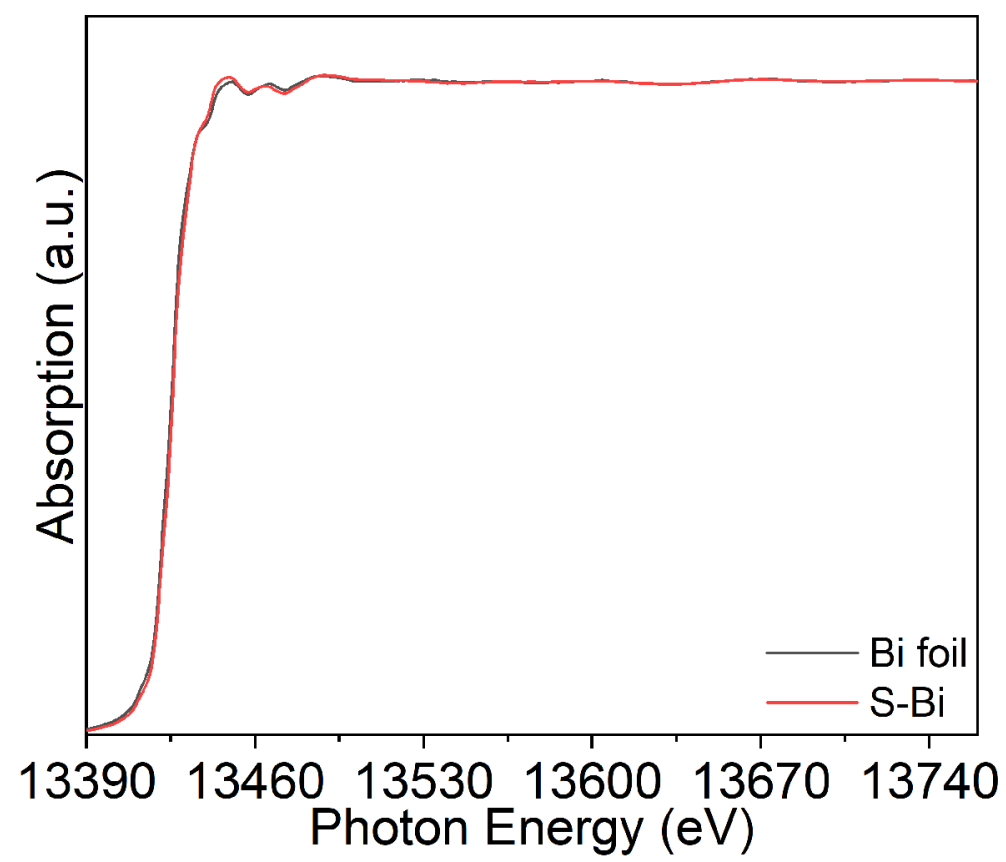

Figure S8. XANES spectra of Bi foil and S-Bi. We can see that the XANES spectra of both $\mathrm{Bi}$ foil and $\mathrm{S}-\mathrm{Bi}$ is almost overlapped, indicating the main component is elemental Bi in S-Bi. Besides, we can see that the peak locate at $13447 \mathrm{eV}$ of $\mathrm{S}-\mathrm{Bi}$ is slightly higher than that of $\mathrm{Bi}$ foil, indicating the higher valance state of $\mathrm{Bi}$. 

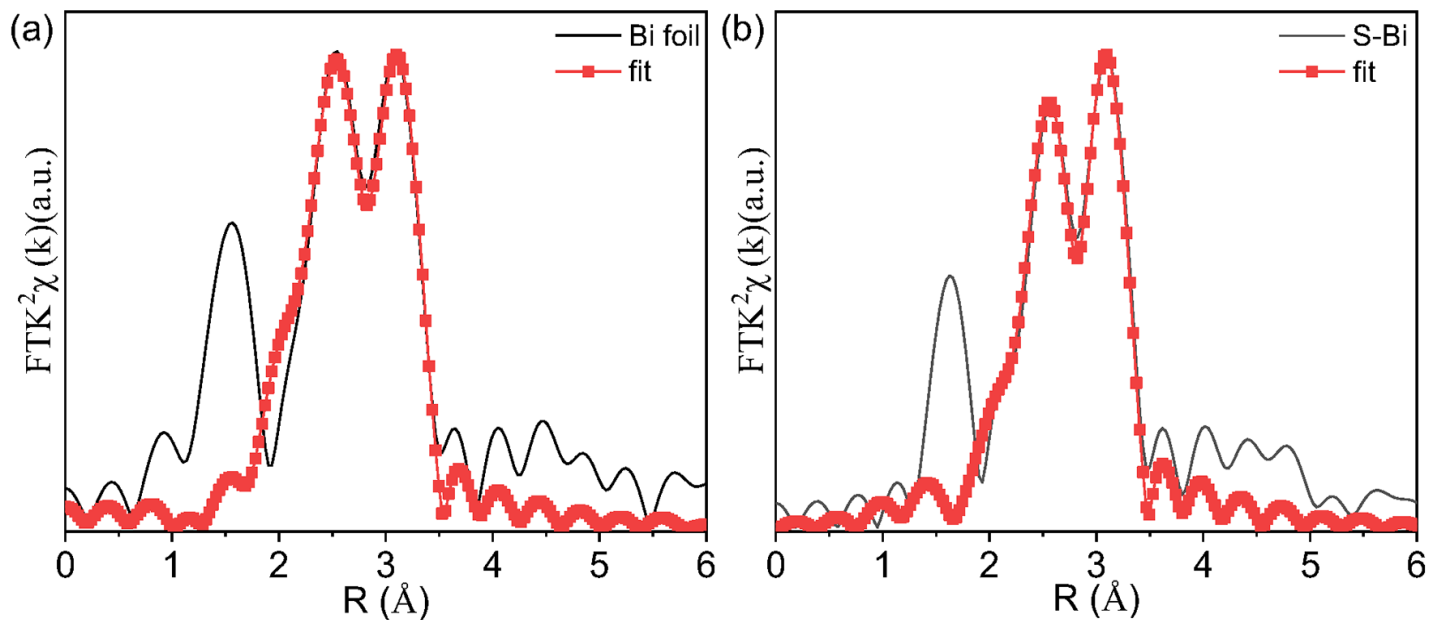

Figure S9. FT $\mathrm{k}^{2}$-weighted spectra in R space of the experimental and corresponding fitting results for (a) Bi foil and (b) S-Bi. 

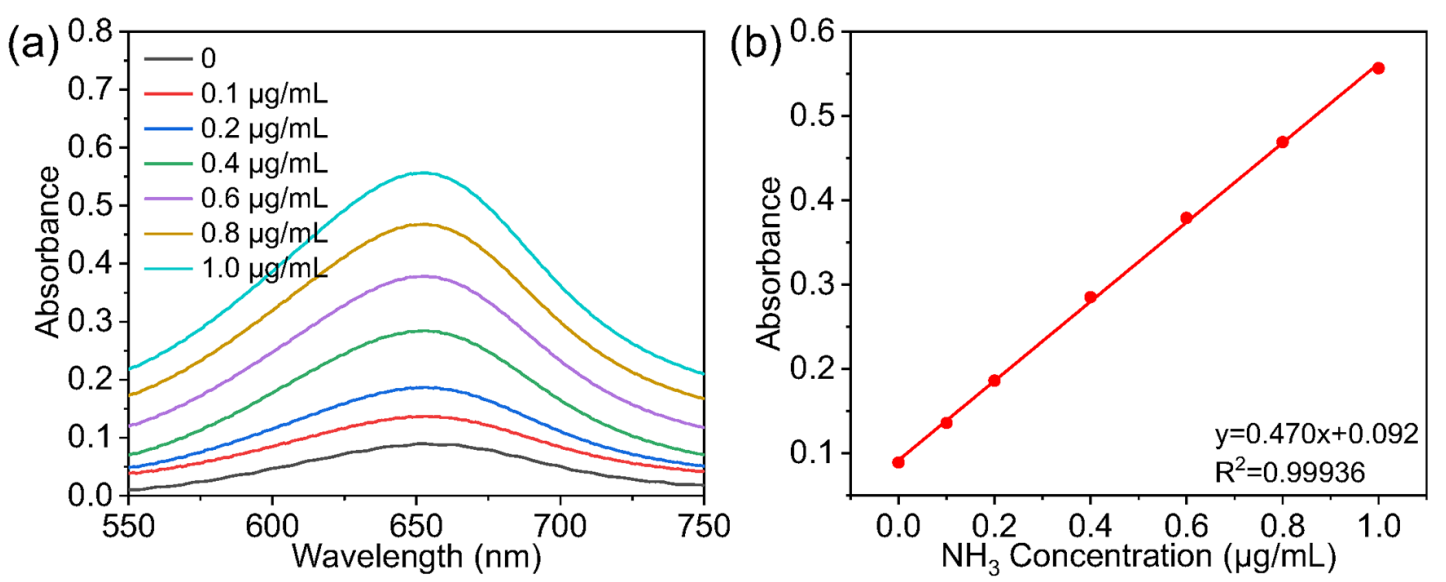

Figure S10. Calibration curve in $0.1 \mathrm{M} \mathrm{NaSO}_{4}$ using ammonium chloride solutions of known concentration as standards. (a) UV-vis curves of indophenol assays after incubated for $1 \mathrm{~h}$ and (b) calibration curve of the standard aqueous solutions. As can be seen from the Figure S10b, the fitting curve shows good linear relation of absorbance with $\mathrm{NH}_{3}$ concentration. 


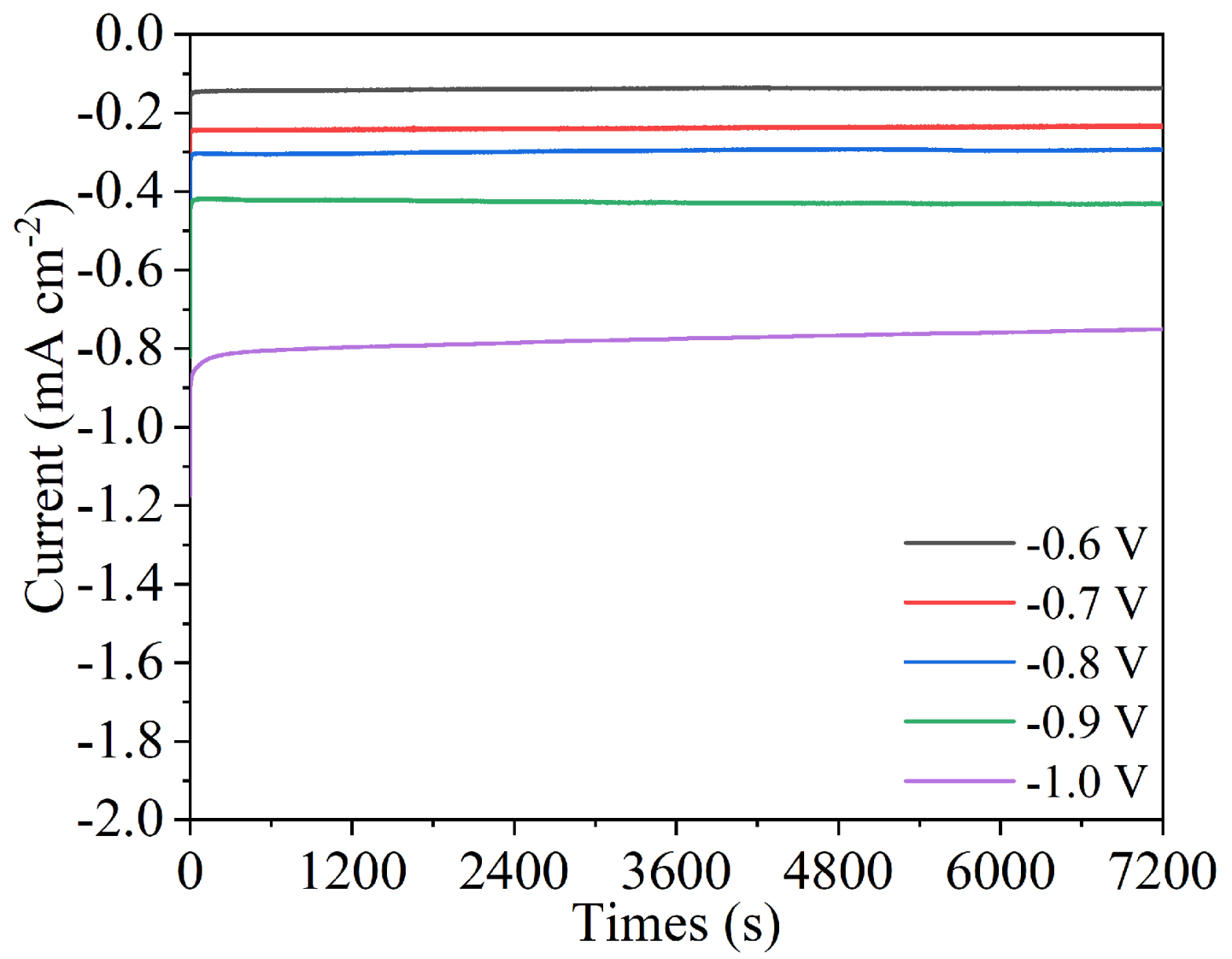

Figure S11. Chronoamperometry results at different applied potentials under $\mathrm{N}_{2}$ flow with a rate of $20 \mathrm{sccm}$ for $2 \mathrm{~h}$. 

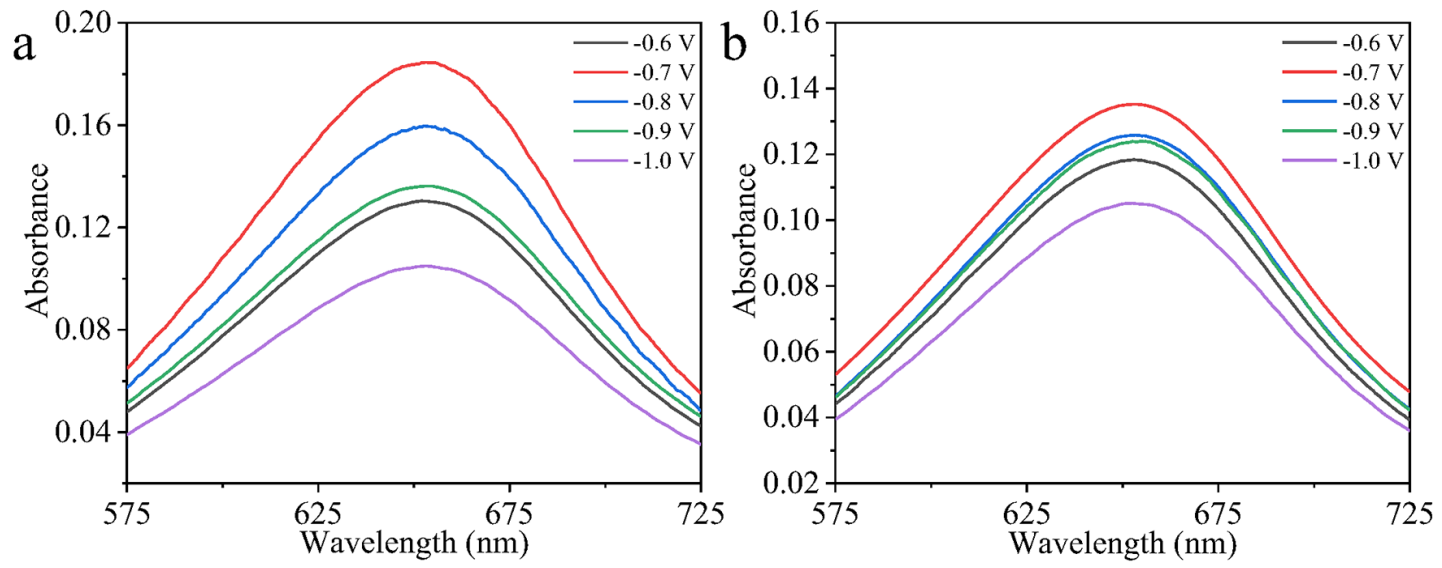

Figure S12. (a) typical UV-vis spectra of the electrolyte in the cathode chamber (50 mL 0.1 $\mathrm{M} \mathrm{Na}_{2} \mathrm{SO}_{4}$ aqueous solution) under different potential and (b) acid trap (5 $\mathrm{mL}$ of $\left.0.5 \mathrm{M} \mathrm{H}_{2} \mathrm{SO}_{4}\right)$ 


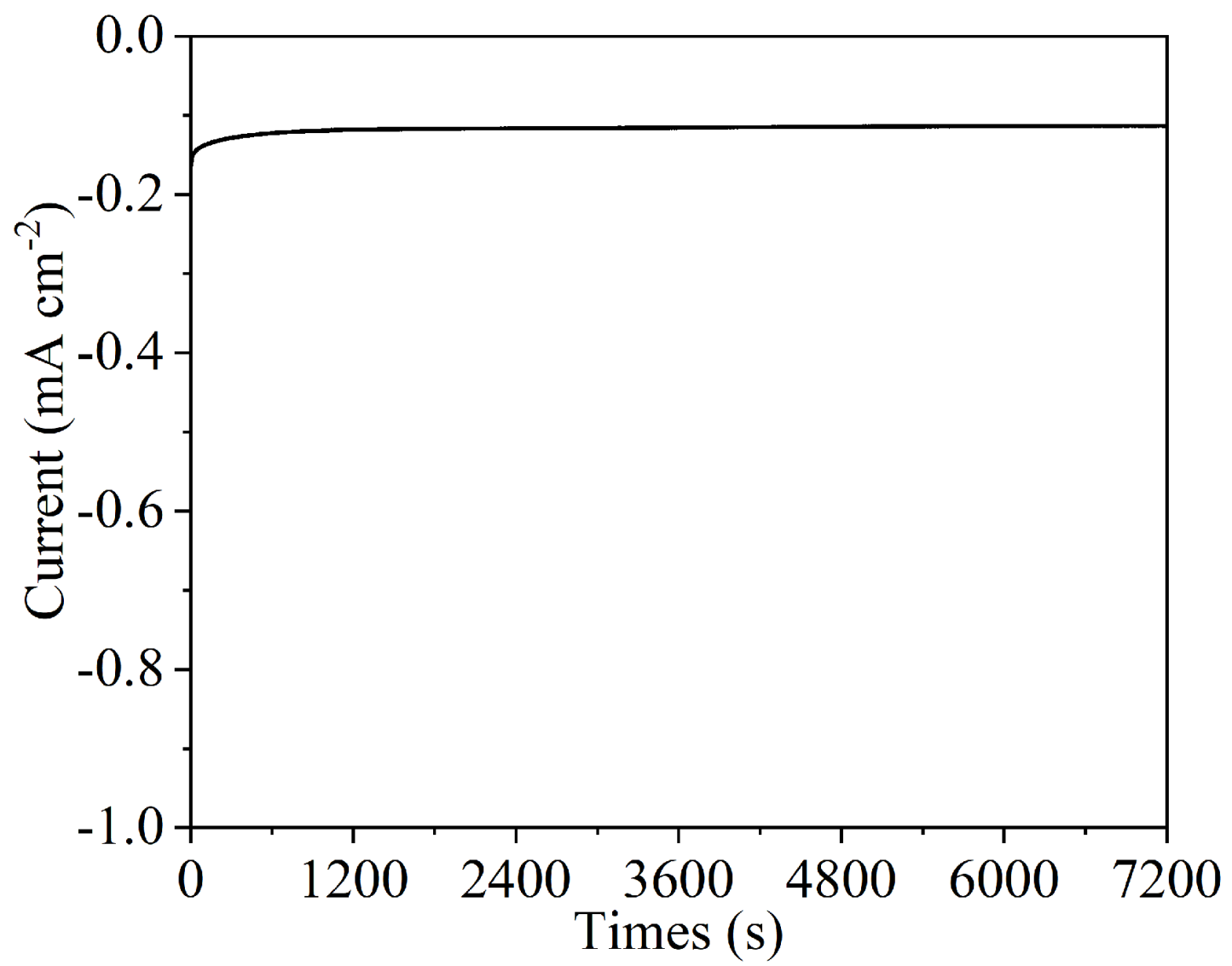

Figure S13. Chronoamperometry results of Bi nanobelt at $-0.7 \mathrm{~V}$ (vs RHE) under $\mathrm{N}_{2}$ flow. 

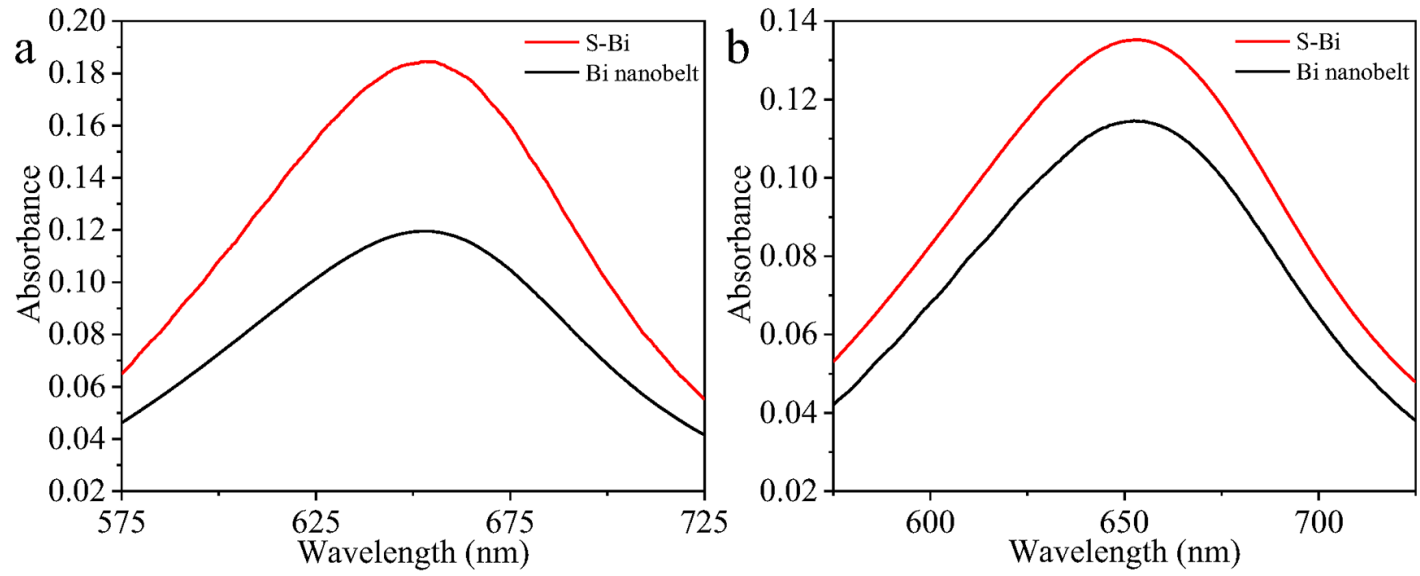

Figure S14. UV-vis spectra of the (a) cathode chamber and (b) acid trapstained with indophenol blue indicator for Bi nanobelt and S-Bi. 

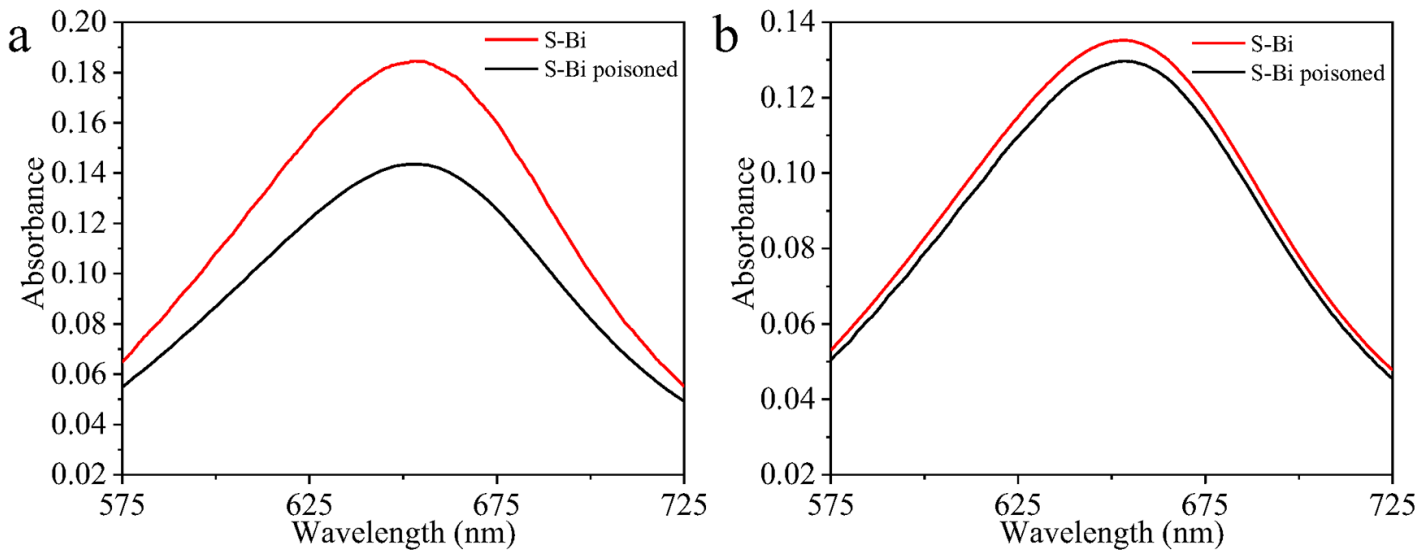

Figure S15. UV-vis spectra of the (a) cathode chamber and (b) acid trap stained with indophenol blue indicator for $\mathrm{S}-\mathrm{Bi}$ and the poisoned $\mathrm{S}$ sites. 

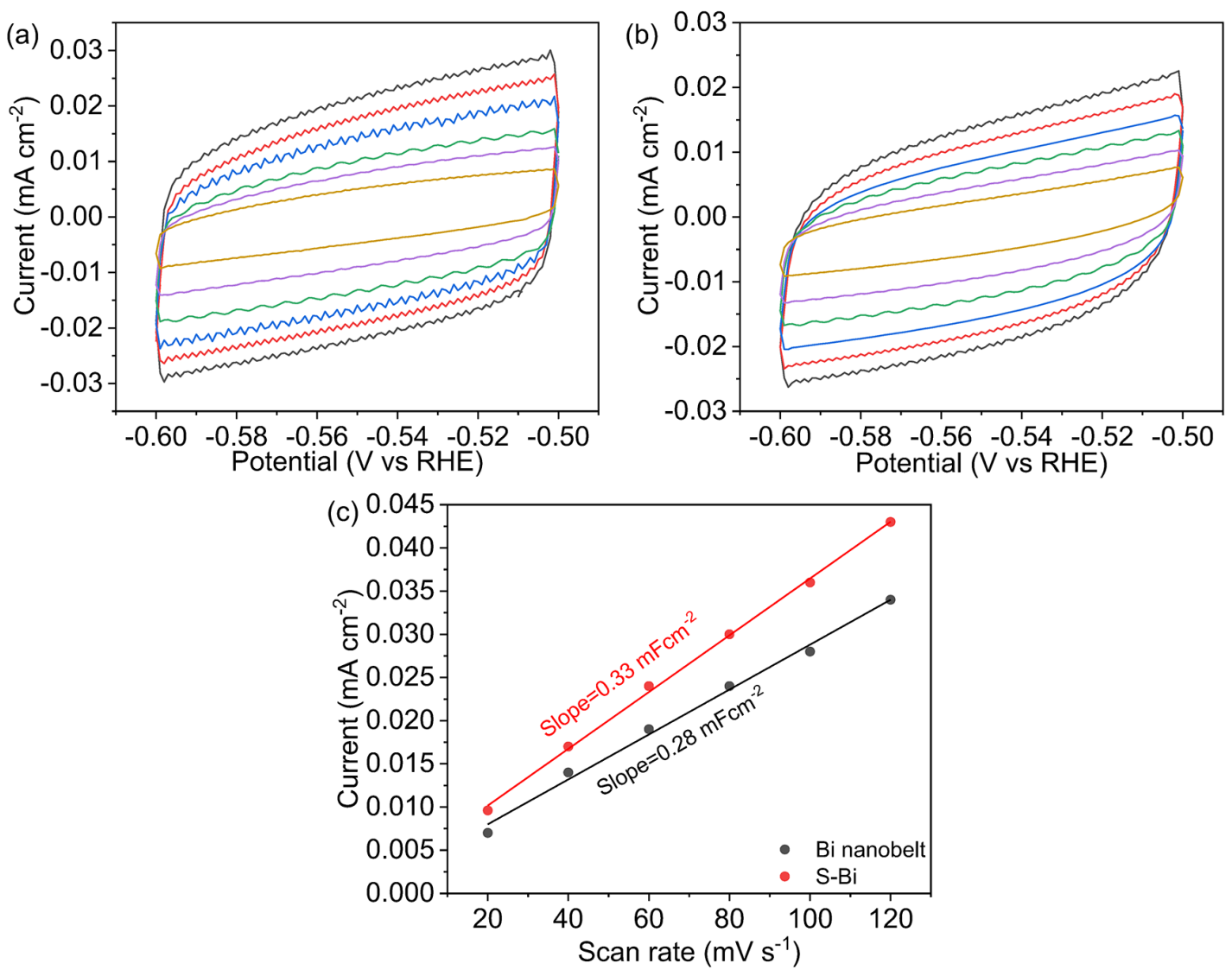

Figure S16. Electrochemical active surface area test of (a) S-Bi and (b) Bi nanobelt under different scan rate. (c) The corresponding $\mathrm{C}_{\mathrm{dl}}$ of $\mathrm{S}-\mathrm{Bi}$ and $\mathrm{Bi}$. 


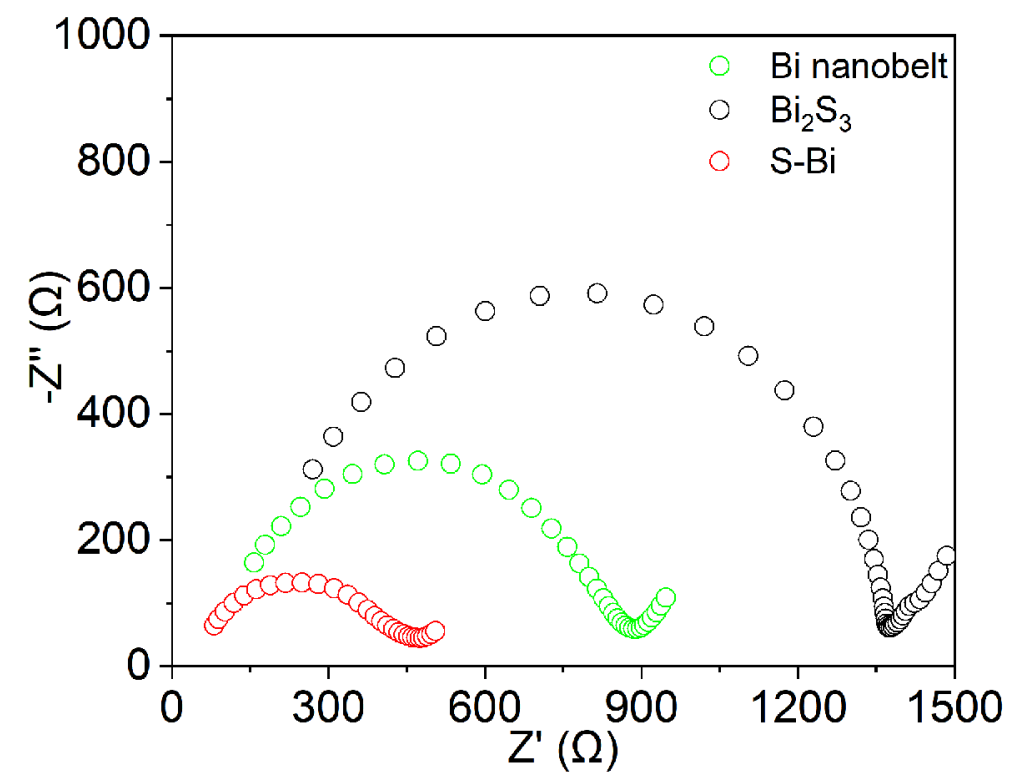

Figure S17. Electrochemical impedance spectra of $\mathrm{Bi}_{2} \mathrm{~S}_{3}$, Bi nanobelt and $\mathrm{S}-\mathrm{Bi}$. 


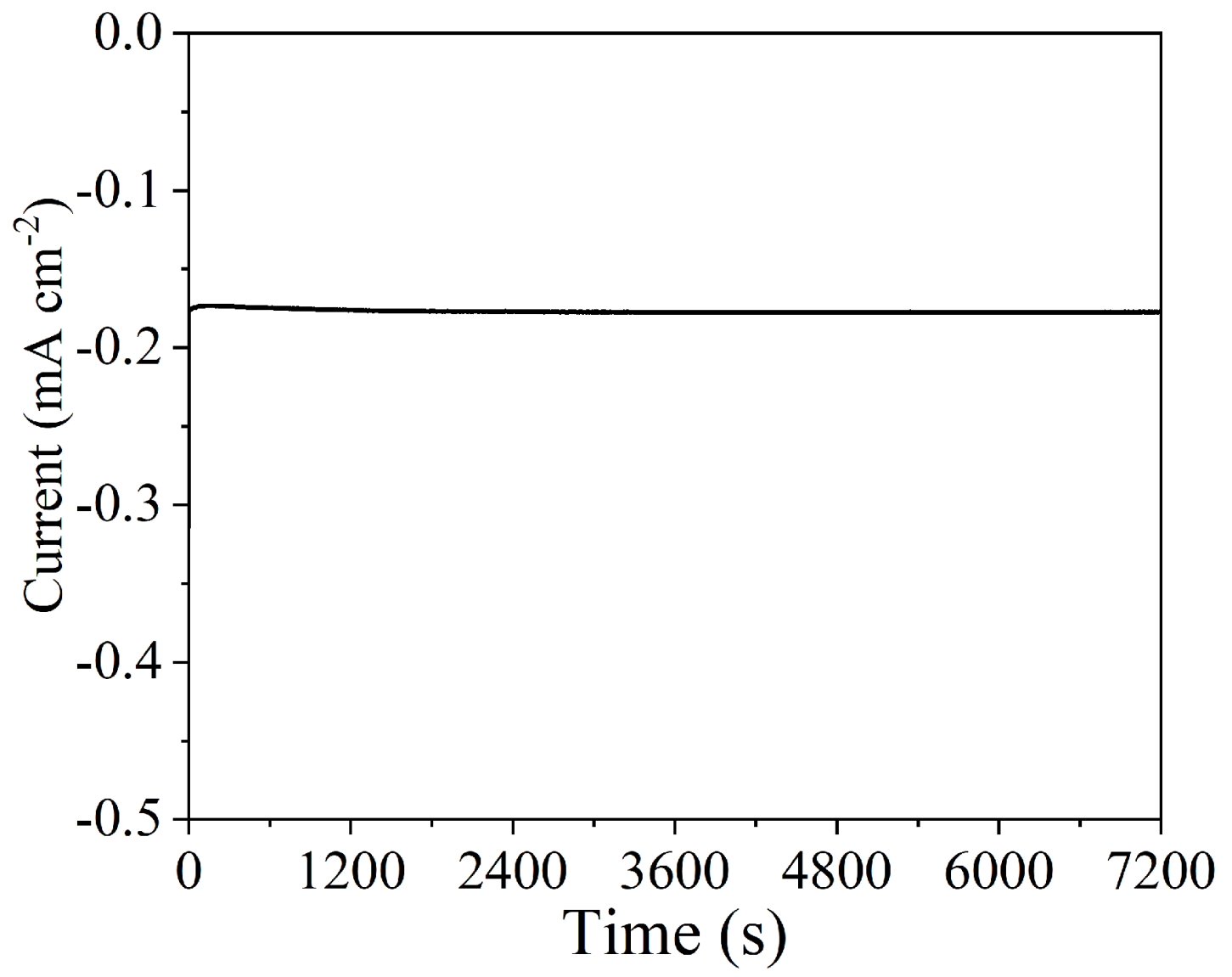

Figure S18. Chronoamperometry results of S-Bi at $-0.7 \mathrm{~V}$ under Ar flow with a rate of $20 \mathrm{sccm}$ for $2 \mathrm{~h}$. 


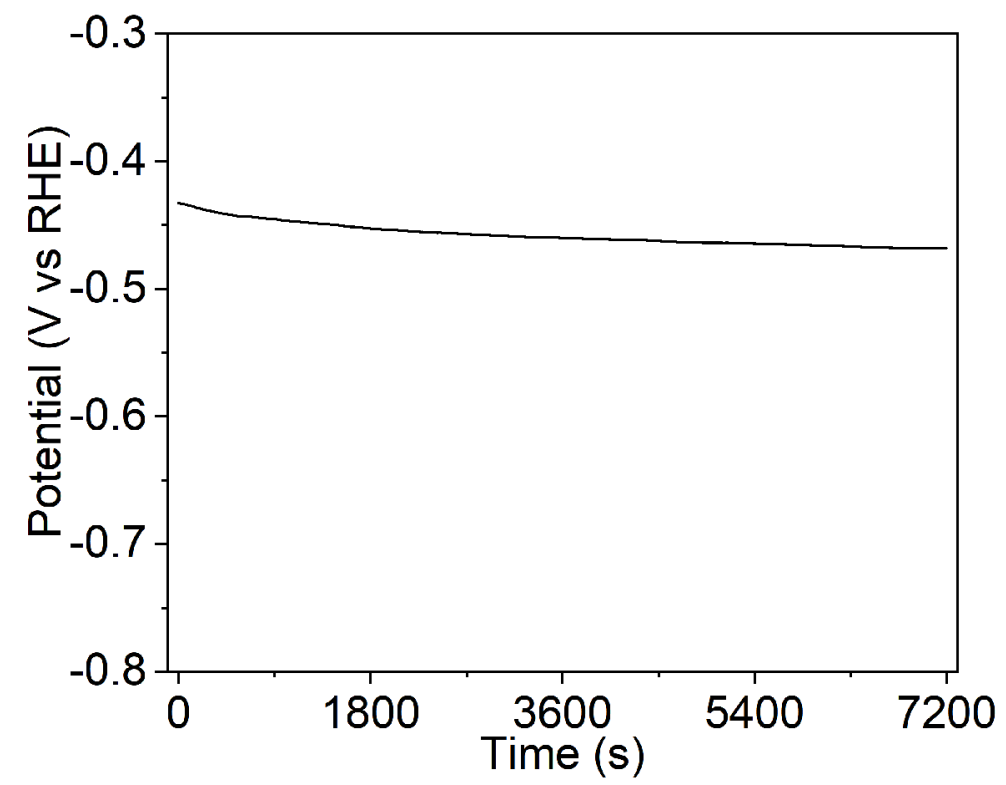

Figure S19. Open circuit potential (OCP) test for $\mathrm{S}-\mathrm{Bi}$ in $0.1 \mathrm{M} \mathrm{Na}_{2} \mathrm{SO}_{4}$ under $\mathrm{N}_{2}$ flow. 


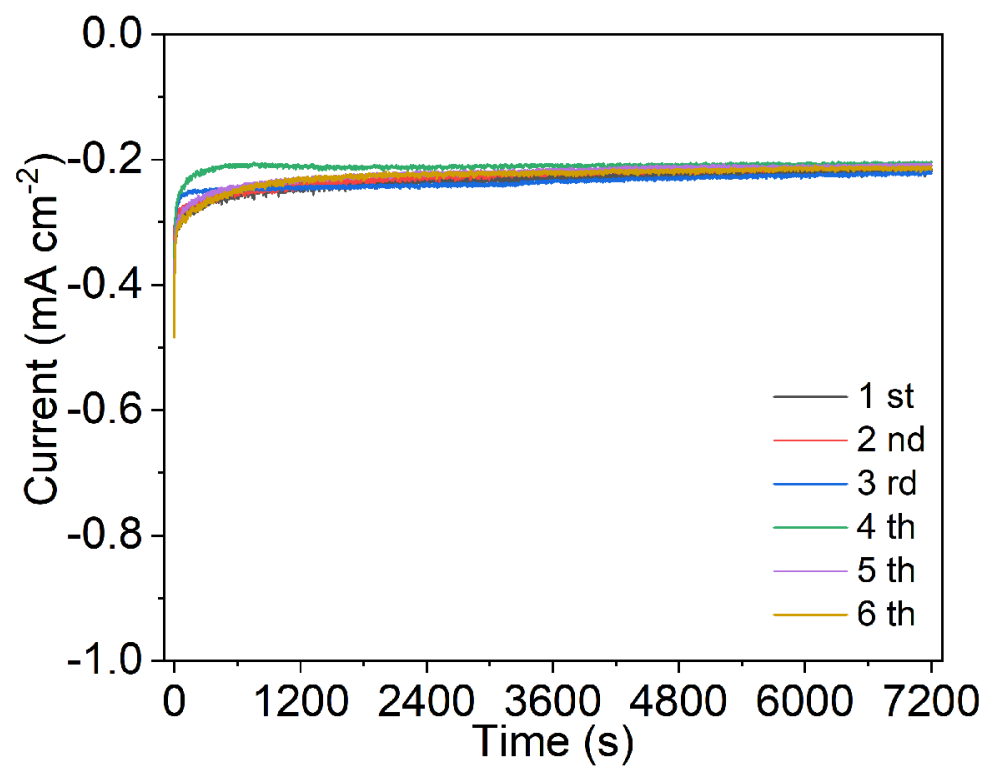

Figure S20. Chronoamperometry curves of S-Bi for 6 circles under $\mathrm{N}_{2}$ flow for the durability test. 

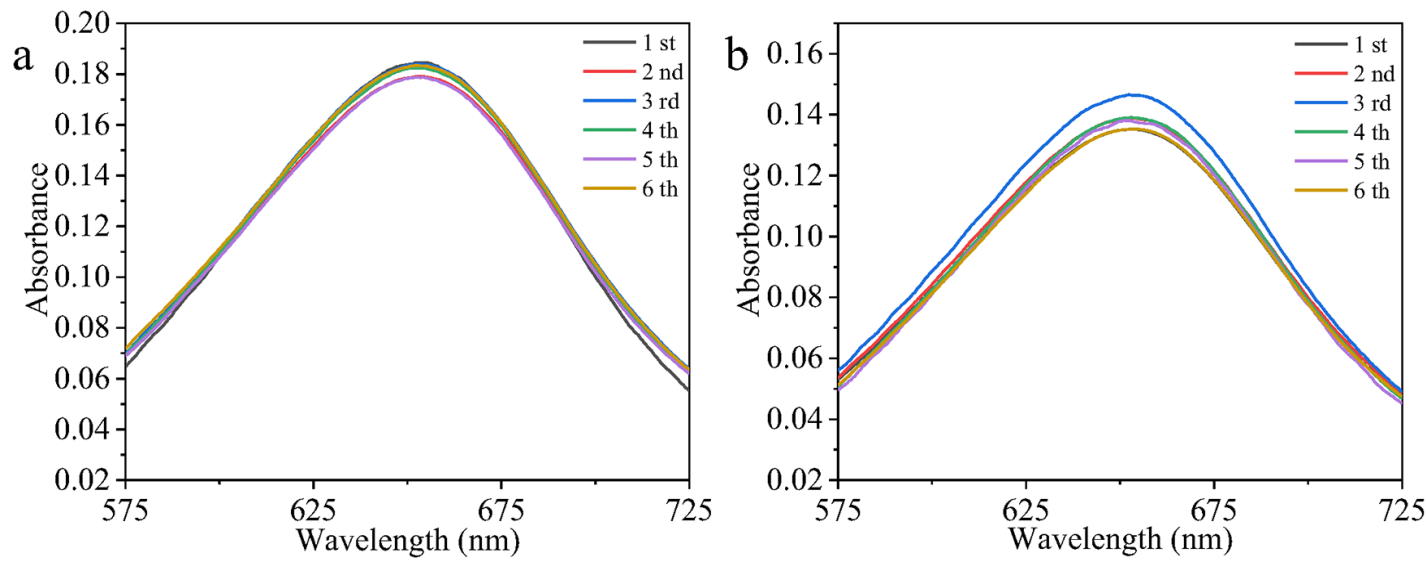

Figure S21. Figure S15. UV-vis spectra of the (a) cathode chamber and (b) acid trap stained with indophenol blue indicator for stability test. 


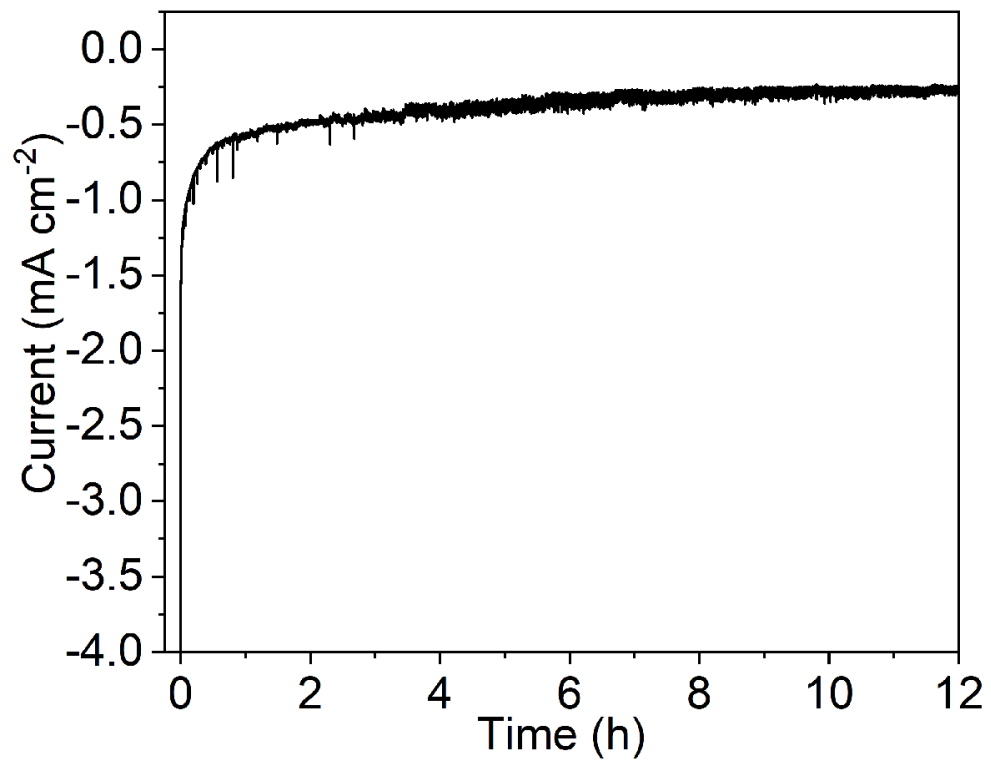

Figure S22. Long time stability test of S-Bi at $-0.7 \mathrm{~V}$ for $12 \mathrm{~h}$.

As can be seen, the S-Bi shows good stability for $12 \mathrm{~h}$. 


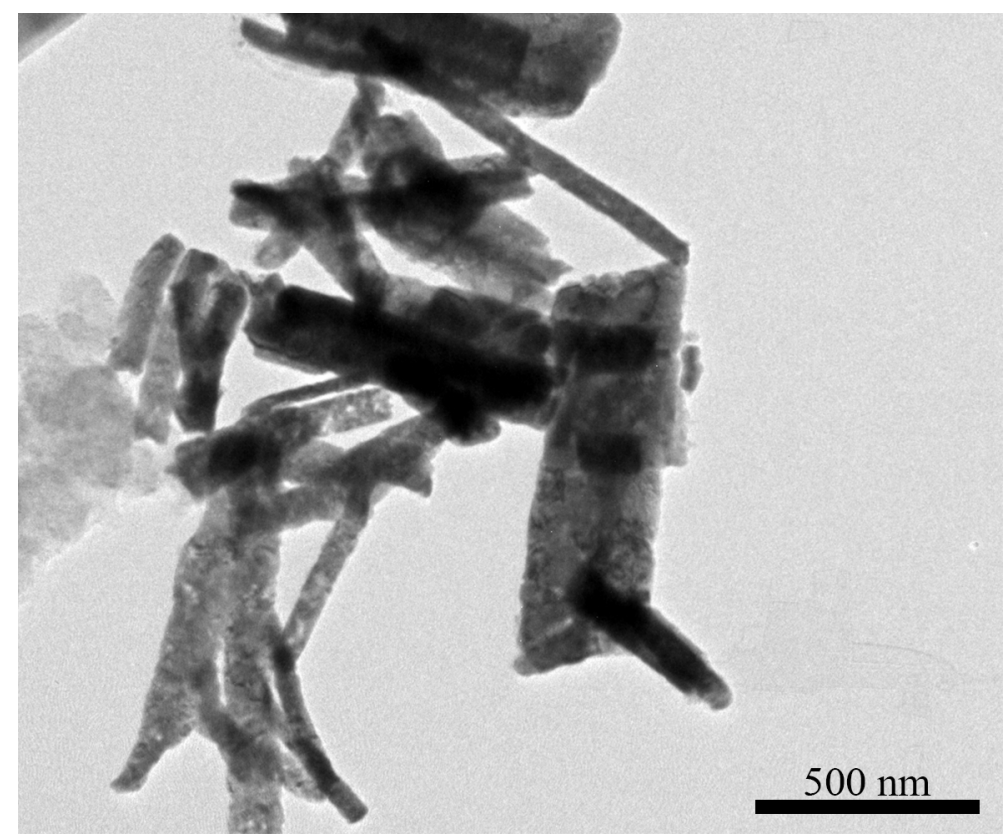

Figure S23. TEM image of S-Bi after NRR test. 


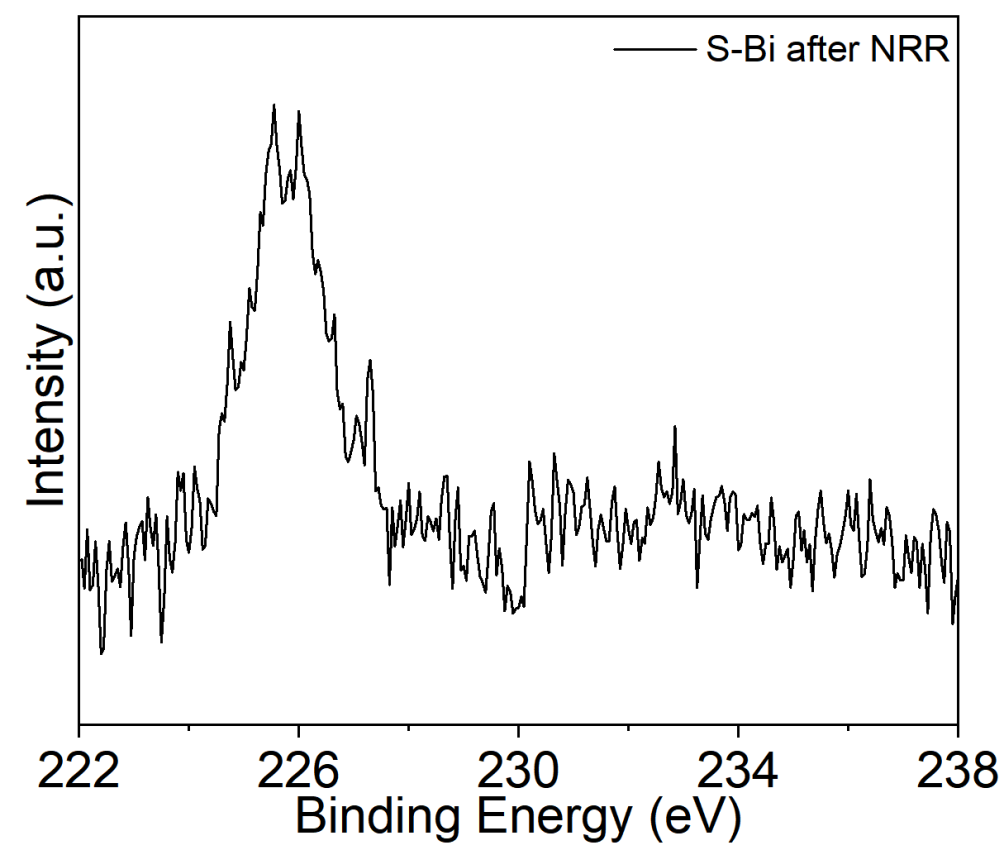

Figure S24. S 2s XPS spectrum of S-Bi after NRR test.

As is mentioned in the previous study, ${ }^{7}$ the $\mathrm{Bi}_{2} \mathrm{~S}_{3}$ has been totally reduced to metallic $\mathrm{Bi}$ with the absence of $\mathrm{S}$ signal. We speculate that the main difference between reported study and our work is because of the because of the different morphology (e.g. length, thickness), inner micro-structure and electrolyte toward the two works. 
(a)

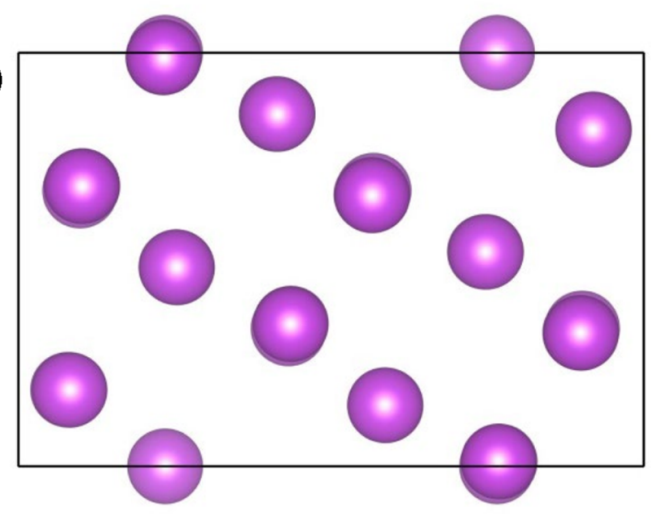

(b)

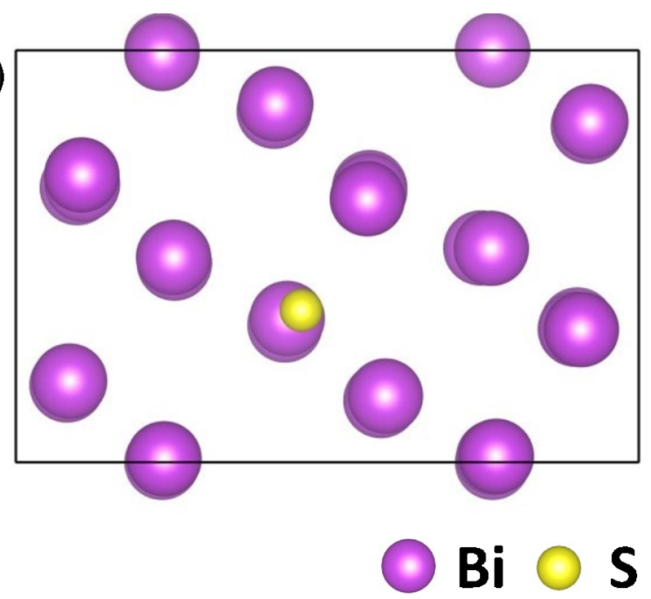

Figure S25. Optimized geometric structures of Bi (110) and S-Bi (110). 

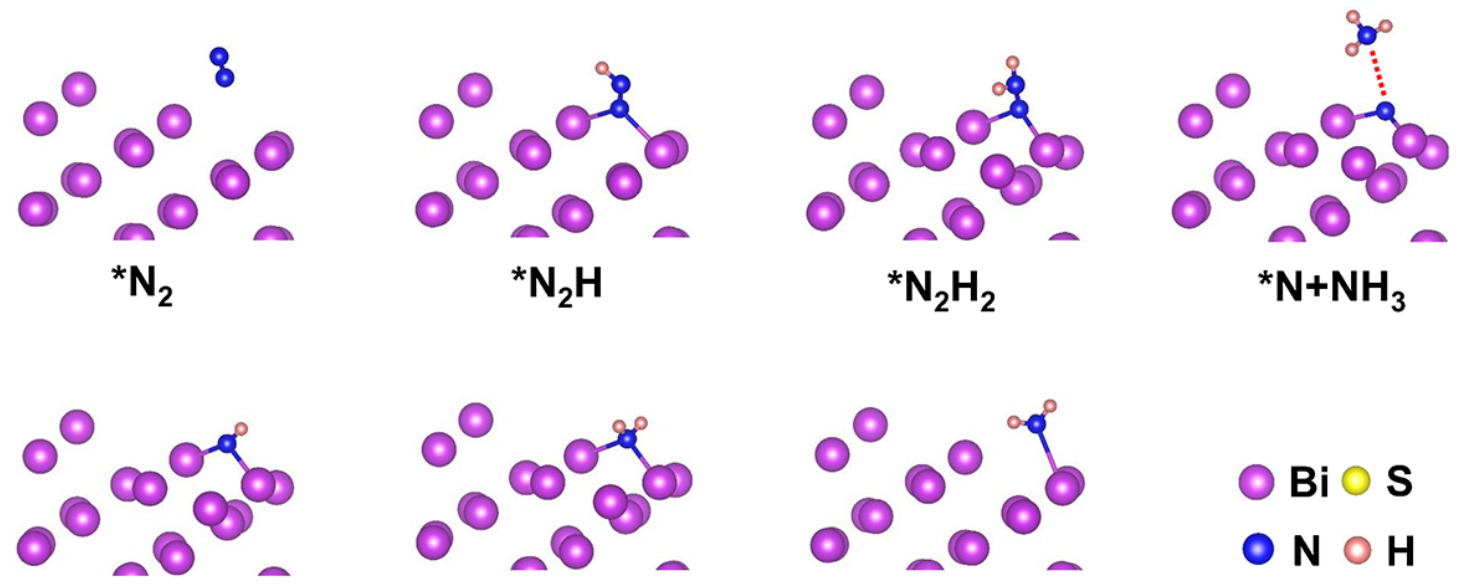

${ }^{*} \mathrm{NH}$

${ }^{*} \mathrm{NH}_{2}$

${ }^{*} \mathrm{NH}_{3}$

Figure S26. Optimized geometric structures of the intermediates for NRR on Bi (110) facet via a distal reaction pathway. 
Table S1. EXAFS data fitting results from Bi foil and S-Bi

\begin{tabular}{|l|l|l|l|l|}
\hline \multirow{3}{*}{ Sample } & Path & $\mathrm{CN}$ & $\mathrm{R}(\AA)$ & $\sigma^{2}\left(10^{-3} \AA^{2}\right)$ \\
\hline \multirow{3}{*}{ Bi foil } & $\mathrm{Bi}-\mathrm{Bi}$ & 3 & 3.07 & 8.69 \\
\cline { 2 - 6 } & $\mathrm{Bi}-\mathrm{Bi}$ & 1 & 2.98 & 9.76 \\
\cline { 2 - 5 } & $\mathrm{Bi}-\mathrm{Bi}$ & 2 & 3.12 & 9.76 \\
\hline \multirow{3}{*}{ S-Bi } & $\mathrm{Bi}-\mathrm{Bi}$ & 2.4 & 3.07 & 7.30 \\
\cline { 2 - 6 } & $\mathrm{Bi}-\mathrm{Bi}$ & 1 & 2.95 & 20.4 \\
\cline { 2 - 6 } & $\mathrm{Bi}-\mathrm{Bi}$ & 2 & 3.09 & 20.4 \\
\hline
\end{tabular}

$\mathrm{CN}$, coordination number; $\mathrm{R}$, bond length; $\sigma^{2}$, Debye-Waller factor; $\mathrm{S}_{0}^{2}$ was fixed to 0.80 as determined from Bi foil. 
Table S2. Ammonia yield and corresponding FE of different samples.

\begin{tabular}{|c|c|c|c|c|c|c|}
\hline Sample & $\begin{array}{l}\text { Potential } \\
\text { (vs. RHE) }\end{array}$ & $\begin{array}{l}\mathrm{NH}_{3} \\
\text { (Electrolyte) }\end{array}$ & $\begin{array}{l}\mathrm{NH}_{3} \\
\text { (Acid trap) }\end{array}$ & $\begin{array}{l}\mathrm{NH}_{3} \text { Yield } \\
\left(\mu \mathrm{gh}^{-1} \mathrm{mg}_{\text {cat }}{ }^{-1}\right)\end{array}$ & $\begin{array}{l}\text { Q } \\
\text { (C) }\end{array}$ & $\begin{array}{l}\mathrm{FE} \\
(\%)\end{array}$ \\
\hline \multirow{18}{*}{ S-Bi } & $-0.61^{\mathrm{st}}$ & 4.08 & 0.28 & 4.36 & 1.01 & 7.36 \\
\hline & $-0.62^{\text {nd }}$ & 4.08 & 0.22 & 4.30 & 1.00 & 7.33 \\
\hline & $-0.63^{\text {rd }}$ & 4.60 & 0.25 & 4.85 & 1.11 & 7.44 \\
\hline & $-0.71^{\mathrm{st}}$ & 9.82 & 0.46 & 10.28 & 1.67 & 10.48 \\
\hline & $-0.72^{\text {nd }}$ & 9.26 & 0.50 & 9.76 & 1.62 & 10.25 \\
\hline & $-0.73^{\text {rd }}$ & 9.78 & 0.58 & 10.36 & 1.69 & 10.43 \\
\hline & $-0.74^{\text {th }}$ & 9.62 & 0.50 & 10.12 & 1.63 & 10.57 \\
\hline & $-0.75^{\text {th }}$ & 9.23 & 0.49 & 9.72 & 1.63 & 10.15 \\
\hline & $-0.76^{\text {th }}$ & 9.78 & 0.46 & 10.24 & 1.71 & 10.24 \\
\hline & $-0.81^{\mathrm{st}}$ & 7.20 & 0.36 & 7.56 & 2.09 & 6.16 \\
\hline & $-0.82^{\text {nd }}$ & 7.15 & 0.41 & 7.56 & 2.10 & 6.16 \\
\hline & $-0.83^{\text {rd }}$ & 7.36 & 0.43 & 7.79 & 2.14 & 6.20 \\
\hline & $-0.91^{\text {st }}$ & 4.50 & 0.30 & 4.80 & 3.02 & 2.71 \\
\hline & $-0.92^{\text {nd }}$ & 4.69 & 0.34 & 5.03 & 3.07 & 2.79 \\
\hline & $-0.93^{\text {rd }}$ & 4.77 & 0.32 & 5.09 & 3.07 & 2.82 \\
\hline & $-1.01^{\mathrm{st}}$ & 1.35 & 0.10 & 1.45 & 5.60 & 0.44 \\
\hline & $-1.02^{\text {nd }}$ & 1.38 & 0.14 & 1.52 & 5.74 & 0.45 \\
\hline & $-1.03^{\text {rd }}$ & 1.37 & 0.14 & 1.51 & 5.76 & 0.45 \\
\hline \multirow{3}{*}{ Bi nanobelt } & $-0.71^{\mathrm{st}}$ & 2.90 & 0.2 & 2.20 & 0.84 & 4.46 \\
\hline & $-0.72^{\text {nd }}$ & 2.93 & 0.24 & 2.17 & 0.88 & 4.18 \\
\hline & $-0.73^{\text {rd }}$ & 2.99 & 0.24 & 2.23 & 0.90 & 4.20 \\
\hline \multirow{3}{*}{$\begin{array}{l}\text { S-Bi } \\
\text { poisoned }\end{array}$} & $-0.71^{\mathrm{st}}$ & 5.45 & 0.35 & 5.80 & 1.20 & 8.22 \\
\hline & $-0.72^{\text {nd }}$ & 5.48 & 0.4 & 5.88 & 1.22 & 8.21 \\
\hline & $-0.73^{\text {rd }}$ & 5.66 & 0.44 & 6.10 & 1.33 & 7.81 \\
\hline
\end{tabular}


Table S3. Computed Bader charge transfer between the adsorbed $* \mathrm{~N}_{2},{ }^{*} \mathrm{~N}_{2} \mathrm{H}$ and the $\mathrm{Bi}$ facets together with the related bond length information for the adsorbed specie

\begin{tabular}{|c|c|c|c|c|c|c|}
\hline & \multicolumn{2}{|c|}{ Charge transfer( $\left.\mathrm{e}^{-}\right)$} & \multicolumn{4}{|c|}{ Bond length $(\AA)$} \\
\hline & $\mathrm{N}_{2}$ & $\mathrm{~N}_{2} \mathrm{H}$ & $\begin{array}{l}* \mathrm{~N}_{2} \\
(\mathrm{Bi}-\mathrm{N})\end{array}$ & $\begin{array}{l}* \mathrm{~N}_{2} \\
(\mathrm{~N}-\mathrm{N})\end{array}$ & $\begin{array}{l}{ }^{*} \mathrm{~N}_{2} \mathrm{H} \\
(\mathrm{Bi}-\mathrm{N})\end{array}$ & $\begin{array}{l}{ }^{*} \mathrm{~N}_{2} \mathrm{H} \\
(\mathrm{N}-\mathrm{N})\end{array}$ \\
\hline Bi (110) & 0.05 & 0.27 & 3.62 & 1.12 & 2.62 & 1.21 \\
\hline S-Bi (110) & 0.07 & 0.28 & 3.62 & 1.12 & 2.61 & 1.22 \\
\hline
\end{tabular}


Reference

(1) Kresse, G.; Furthmüller, J. Efficiency of Ab-initio Total Energy Calculations for Metals and Semiconductors using a Plane-wave Basis Set. Computational materials science 1996, 6, 15-50.

(2) Ernzerhof, M.; Scuseria, G. Assessment of the Perdew-Burke-Ernzerhof exchange-correlation functional. J. Phy. Chem. C 1999, 110, 5029-5036.

(3) Perdew, J.; Burke, K. and Ernzerhof, M. Generalized gradient approximation made simple. Phys. Rev. Lett. 1996, 77, 3865.

(4) Kresse, G.; Joubert, D. From Ultrasoft Pseudopotentials to the Projector Augmented-wave Method. Phys. Rev. B 1999, 59, 1758.

(5) Skulason, E.; Bligaard, T.; Gudmundsdóttir, S.; Studt, F.; Rossmeisl, J.; Abild-Pedersen, F.; Vegge, T.; Jonsson, H.; Nørskov, J.; A theoretical Evaluation of Possible Transition Metal Electro-catalysts for $\mathrm{N}_{2}$ reduction. Phys. Chem. Chem. Phys. 2012, 14, 1235-1245.

(6) Nørskov, J.; Rossmeisl, J.; Logadottir, A.; Lindqvist, L.; Kitchin, J. R.; Bligaard, T.; Jonsson, H.; Origin of the Overpotential for Oxygen Reduction at a Fuel-cell Cathode. J. Phy. Chem. B 2004, 108, 17886-17892.

(7) Zhang, Y.; Li, F.; Zhang, X.; Williams, T.; Easton, C. D.; Bond, A. M.; Zhang, J.; Electrochemical Reduction of $\mathrm{CO}_{2}$ on Defect-rich Bi Derived from $\mathrm{Bi}_{2} \mathrm{~S}_{3}$ with Enhanced Formate Selectivity. J. Mater. Chem. A. 2018, 6, 4714-4720. 